\title{
Reaching out to people struggling with their lives: a discourse analysis of answers from Internet-based services in Norway and Sweden
}

This article was published in the following Dove Press journal:

Psychology Research and Behavior Management

14 September 2012

Number of times this article has been viewed

\author{
Anders Johan W Andersen' \\ Tommy Svensson ${ }^{2}$ \\ 'Department of Psychosocial Health, \\ University of Agder, Grimstad, \\ Norway; ${ }^{2}$ Department of Behavioural \\ Sciences and Learning, Linköping \\ University, Linköping, Sweden
}

\begin{abstract}
The Internet has enlarged the scope of human communication, opening new avenues for connecting with people who are struggling with their lives. This article presents a discourse analysis of 101 responses to 98 questions that were posted on 14 different Internet-based mental health services in Norway and Sweden. We aimed to examine and describe the dominant understandings and favored recommendations in the services' answers, and we reflected upon the social consequences of those answers. The services generally understood life struggles as an abnormal state of mind, life rhythms, or self-reinforcing loops. Internet-based mental health services primarily counsel service users to seek help, talk to health care professionals face-toface, and discuss their life struggles openly and honestly. They also urge service users to take better care of themselves and socialize with other people. However, such answers might enhance the individualization of life problems, masking social origin and construction. Consequently, the services are challenged to include social explanations in their answers and strengthen their responsibility to amplify peoples' messages at a societal level. Potentially, such answers could strengthen democratic structures and put pressure on social equity.
\end{abstract}

Keywords: depression, e-mental health, health psychology, Internet, public health

\section{Introduction}

"I can't stand this anymore. What's the point of living?" Posted on a Swedish Internetbased service in 2011, this message illustrates a common plea. How do the services respond to such messages? How do Scandinavian societies respond to people struggling with their lives? This is the topic of the present article. We used communications collected from Internet-based mental health services in Norway and Sweden as a springboard to examine how Scandinavian societies understand and perceive people who are engaged in life struggles.

Life struggles have been described and explained differently throughout history. During the 20th century, understanding and description of phenomena related to life struggles increased rapidly, yielding a complex tapestry that depended heavily on the academic disciplines. Earlier investigations assigned life struggles to specific neurochemical mechanisms, ${ }^{1}$ questions of diet, ${ }^{2}$ depressogenic thoughts and assumptions, ${ }^{3}$ the search for life's meaning, ${ }^{4}$ and lack of social inclusion. ${ }^{5}$ Different discourses exist side by side. ${ }^{6}$ Moreover, service users ${ }^{7,8}$ and policymakers ${ }^{9}$ wrestle with the same phenomena. Researchers strongly emphasize how commercial interests influence society's understanding and treatment of depression. ${ }^{10}$ Indeed, history has mapped the gradual empowerment of different institutions, scientific disciplines, and professionals as they define and redefine the "what" and the "how" of life struggles. ${ }^{11}$ 
This article is part of a research project that aims to explore, describe, and analyze different discourses of mental health in Norway and Sweden using material from Internetbased services. ${ }^{12-14}$ The aim of this paper is to examine and describe the dominant understandings and favored recommendations in the answers from the web services and reflect upon their social consequences.

\section{Materials and methods Data collection and material}

In 2009, we systematically mapped existing websites published in Norwegian and Swedish, using keywords inspired by two recognized national email services. The Norwegian keywords were "psykisk helse" (mental health), combined with "meldingstjeneste" (message service), "svartjeneste" (answering service), or "mailtjeneste" (email service). The Swedish keywords were "psykisk hälsa" (mental health), combined with "nättjänst" (webservice), "mailtjänst” (e-mail service), "mail nätforum" (email web forum), "chatte mail forum" (chat email forum), or "jourmail" (emergency mail). The search engines used in this mapping (ie, Google and Kvasir) yielded 502 hits. After briefly reviewing the hits, we narrowed the scope of our search by excluding irrelevant sites (ie, advertisers, blogs, conferences, different sorts of word documents). Snowball sampling (ie, including references and recommendations to other websites mentioned on relevant sites) increased the sample. ${ }^{15}$

We included only websites offering mental health services by email or posted messages that provided an easily accessible service with publicly available communication, demanded no membership requirement, and appeared to post only unedited questions from service users. At the completion of this sampling process, we conducted a study analyzing service users' messages at the selected web services. ${ }^{13}$ "Life struggles" (ie, sadness, loneliness, depression, despair, lack of meaning, deadlocked situations, suicidal thoughts) emerged as one of eight categories that service users consider important. ${ }^{13}$ The present article explores the services' answers to the service users' requests in this category.

Using these criteria of inclusion, we ended up with a sample of 14 websites (seven Norwegian and seven Swedish), including two privately owned and operated services, two services operated by nongovernmental organizations, and ten publicly owned and operated services. Nine of the services targeted adolescents and young people; the remainder targeted the general public. Responders were mostly health professionals (eg, doctors, family therapists, psychologists, school nurses, and/or social workers), although some were described merely as "experts". One service relied on nonprofessional responders and another used a mix of professionals and experienced service users. The data were collected between October 2010 and June 2011, and consist of 98 requests ranging from five to 3000 words, and 101 answers ranging from 50 to 1500 words.

\section{Discourse analysis}

Discourse analysis encompasses different approaches examining how people and societies create order out of complexity and how human thinking shapes different practices and produces realities. ${ }^{16-18}$ It enabled us to reveal dominant understandings and favored recommendations in the answers from the web services, and allowed critical reflections upon their social consequences. Thus, discourse analysis enhances a bottom-up research perspective regarding the social function of hegemonic discourses. ${ }^{19}$

Internet-based mental health services present communication not only as information for potential service users but also as a publicly available resource that amplifies the challenges people face in everyday life. Therefore, it is possible to view our data both individually and as a unified corpus of societal knowledge. ${ }^{20}$ Our analysis viewed the data as one single document divided into two main sections, ie, service users' requests and answers from the services. We viewed the data as a complete document in which one might find great variation and nuances as well as preferred perspectives and acknowledged ways of understanding life struggles. The analysis did not consider possible differences in the data material due to the backgrounds of the service users (eg, age, gender) or the services (eg, sector, professional background).

To achieve an indepth familiarity with the data, we began the analytic process by reading and rereading the submitters' requests and the answers from the services..$^{21}$ As a result of this time-consuming rumination process, we discerned some patterns to the answers. Variation was used as a lever in the analytic process. ${ }^{22}$ Accordingly, we used both outspoken and silenced variation in order to make the choices of the services more visible. ${ }^{23}$

Initially the first author suggested some dominant patterns. These suggestions were cross-checked by the second author, and the final patterns were decided by the authors together. Our interpretations are discussed under the headings of understanding life struggles and favored recommendation for handling life struggles. Finally, we reflected upon possible social consequences of the findings from the discourse analysis. 


\section{Ethical and methodological considerations}

Given the openness and availability of websites, as well as their privacy policies and anonymous nature, we judged it ethically acceptable to analyze posted communications without seeking informed consent. Similar to the approach used by other studies ${ }^{24}$ and supported by textbooks in methodology, ${ }^{15}$ this approach was approved by the National Committee for Research Ethics, which did not require licensing or special ethical approval as long as the information we collected was publicly available and the services provided technical solutions that guaranteed total anonymity.

This study viewed its data as one complete document. By doing so, we risk obscuring the fact that the answers were delivered by different services and answerers with different backgrounds. Additionally, the answers were directed to different service users in different situations in life. Consequently, the discussions presented here might be criticized for being too general, and lessening contextual information. This was not our intention. We aimed to explore and describe the dominant understandings and favored recommendations in answers from Internet-based mental health services. Therefore, we argue that our approach is appropriate for examining the discourses that dominate throughout the entire material. Discourse analysis seems particularly appropriate for exploring the "what" and "how" of different practices. ${ }^{19}$ However, because all quotations presented here to illustrate our finding were translated into English by the authors, we acknowledge the risk of unintentional translator bias. ${ }^{25}$

\section{Results and discussion}

Our interpretations of the answers are presented following the aim of the article. First, we examine how the answers construct dominant understandings of life struggles in the services. Second, we examine and describe the services' favored recommendations for handling life struggles. If not otherwise explained, all the quotations are collected from our data material.

\section{Understanding life struggles}

Many answers began by interpreting and then reframing the service user's messages. Although expressed differently, the core issue of these representations appears to renegotiate the service user's understanding, description, or characterization of her/ his own concerns. Such reframing might be understood as an important part of the answers for some of the services. It renders the messages more equivocal, opening new possibilities for handling the presented concerns. Internet-based services initially tend to normalize service users' concerns and situations with statements like, "All people feel blue sometimes" or "Anyone can become depressed." Such statements echo the chorus of "Everybody Hurts", a popular recording by the rock group R.E.M. ${ }^{26}$ These are ordinary life struggles. Thus, one might argue that Internet-based services recast life struggles as common knowledge:

"These are heavy thoughts and at the same time something that probably everyone might recognize - what is the meaning of life, why am I here, what does the world look like, etc. When you are a teenager it is usual to start thinking about yourself, who you are and of your surroundings. Solid and everlasting answers don't exist since people and their surroundings change and develop constantly."

Such answers might make people feel less like aliens on a strange planet, reducing any feeling of deviance. Messages of acceptance and recognition include people in humankind. However, one might also argue that the services used normality mainly as an interim stop on the way to challenging submitters' understanding of the world:

"Most people lie from time to time, they refrain from telling the truth, in order to avoid hurting anyone or to avoid discomfort like someone gets angry. The problem usually is that a lie breeds more lies, you have to lie again in order to hide the first lie and so on. ... Lying becomes a pattern difficult to break. It is best to tell the truth and meet whatever discomfort that truth leads to, straight away."

Briefly stated, Internet-based services tell their users that although your way of dealing with your life struggles is quite normal, it is an inappropriate coping strategy. It reinforces your life struggles and makes things worse. Such explanations mostly serve as a starting point, introducing the service user to new ways of viewing her/his own concerns and challenging her/his understanding of the situation. One responder wrote, "I' $m$ curious that you can be 'one hundred percent' certain that you are feeling like this because you're a teenager? Have you had a physical examination? Obviously, your troubles might have a physical cause." Services often use age to normalize concerns but that strategy does not work when the service user suggests the same approach. One might argue that the services value the art of disturbance in the sense that they aim to present different perspectives than the service user. In doing so, they challenge the users' explanations and coping strategies. Thus, a reframed question might 
help service users to change their perspectives, forcing them to review their understandings. Such answers reveal dominant discourses in the services' general understanding of life struggles.

We identified three dominant understandings, ie, life struggles as an abnormal state of mind, life struggles as life rhythms, and life struggles as a self-reinforcing loop.

\section{Life struggles as an abnormal state of mind}

Relating an answer to physical examination (see above) might suggest the possibility of physical or mental abnormality: "If you don't sleep and eat regularly, it's like driving a car without gas. Your car breaks down." These answers tend toward bodily metaphors (eg, "catching a cold") and relegate life struggles to medical diagnosis: "It is difficult for me to give you a diagnosis in a column like this, but I think you might have what is called PTSD - post traumatic stress disorder." Although service users seldom ask for a diagnosis, counselors try to clarify a user's state of mind in diagnostic terms: "It is difficult to say anything with certainty about your struggles without consultation and thorough investigations but you describe thoughts and behavior consistent with depression." Furthermore, a precise diagnosis requires thorough examinations by health care providers. Therefore, the discourse is founded on an exclusionary dichotomy between sickness and health, ie, an either/or mindset. When a service user reported overall unhappiness, the service advised that:

"[You] need to reveal what is nurturing in your life and what is debilitating. You have children, they are clearly more nurturing than debilitating? ... Your partner, if you have ... Is he nurturing or debilitating? ... Your job, nurturing or debilitating? ... You see the pattern? I'm sure that if you examine your life, you will see where the problem lies.

Then, you grab your bad apples one by one."

Thus, life struggles become an unnecessary and abnormal state of mind, the cause of which must be erased by a targeted and systematic approach. Simplistically, this way of thinking resembles the definition of health as the absence of disease. ${ }^{9}$ Life struggles become an unhealthy and unwanted state of mind.

\section{Life struggles as life rhythms}

Another perspective rejects the black and white dichotomy discussed earlier, emphasizing the colors of life: "It is important to recognize that things are not either/or, but both/ and simultaneously. Both good and bad, both fantastic and horrible, perfect and imperfect. You need to acknowledge the fact that life sometimes seems meaningless while life at the same time is both meaningful and comprehensive." This approach favors yin/yang thinking, wherein humans seek balance: "Imbalances in life between things that bring joy and make you feel happy and stressful things making you sad and worry. Living in a situation of discomfort and despair might make anyone depressed." In other words, life struggles are inevitable, ebbing and flowing in a continuum that opens the possibilities of hope. Somehow, we have moved back to the ordinariness of life struggles and the message from R.E.M, ie, everybody hurts sometimes. ${ }^{26}$ This discourse emphasizes the last word, "sometimes", and by doing so implies the necessity of and hope for change. The services might express this as follows: "Although you right now feel that your life is in complete darkness. Things will change. Life might contain great suffering but even great joy. Life is not always as hard as you feel these days." Life struggles are viewed as an inevitably part of the rhythms of life. Life changes and everybody needs to find a way to cope with such struggles. It is not so much a state of mind, but it has similarities with the notion of health as an ongoing process. $^{27,28}$

\section{Life struggles as self-reinforcing loop}

Other answers resemble the life rhythm approach but have different nuances. In these answers, life struggles are viewed not as inevitable but rather as hurdles that are related to specific situations. Such answers strongly value the process of recovery:

\begin{abstract}
“Don't judge yourself, you have done the best you could, your troubles are not strange, your situation has been so troublesome that you couldn't have handled it differently, you haven't known how or what to do. Now you have reached a point where you recognize that you have to do something, your first step was to write to this page. Very good! You have started your 'journey' towards recovery and rebuilding your life as you want it."
\end{abstract}

Self-reinforcement emphasizes coping strategies. Difficult situations require different strategies. However, strategies that reinforce difficulties can make life struggles seem even bigger. In other words the question is not what one looks at but what one sees: "You are so concerned with the experience of being alone, that it seems like you're not able to think of something else. ... I think you are stuck in your own mind. ... It seems like you constantly wear the 'I am lonely' glasses." A cautionary note here is that an individual's 
thought process shapes her/his perception of life, potentially risking self-fulfilling prophecy:

"You are really caught in a vicious circle of unhappiness, strong unpleasant feelings, repeated attempts to manage your life and your tough situation by self-harm, which only makes you feel even worse, negative self-image, sense of perpetual failures, falling confidence and avoiding the difficulties in relating to other people ... Your coping strategies make it even worse."

Thus, negative thinking leads to feelings of distress and despair, trapping people in a never-ending, self-reinforcing loop. Counselors use this approach to suggest that life struggles result from an individual's self-perception, similar to attribution theory and the traditions of cognitive therapy. ${ }^{3}$

\section{Favored recommendations for handling life struggles}

Despite differences in the understanding of life struggles, the services unite in persistent recommendations that their service users need to seek help: "In order to feel better, it is important that you seek help. We believe your life can improve with proper help." Services strongly encourage submitters to seek help and talk openly and honestly to other people about their life struggles: "In order to be understood and receive proper help, it is necessary for you to be completely honest and tell everything of how you think, feel and how you are to those helping you." Most services convey such advice as an imperative (eg, "Seek help and your life will become better and easier"), but sometimes express their response as a mild request or proposal: "Is there anyone at school you can talk to for example a teacher, a school nurse, a counselor?" In this study, talk and tell was the most dominant answer.

This recommendation is consistent with recent research findings. Studies indicate that the use of Internet-based services increase ${ }^{29}$ and complements contact with regular mental health services. ${ }^{30-33}$ Thus, Internet-based services may be viewed as a first step towards a more conventional mental health system that emphasizes an interconnection between health care providers. ${ }^{12}$ However, this answer remains difficult and ambiguous. It is not as if service users do not seek help; on the contrary, some plead for help - online. ${ }^{14}$

Although information about where to find help is vitally important and might be regarded as help in its own right, service responders seem less empowered by the opportunity to offer help online. Their primary recommendation might show a lack confidence that results from their inability to meet face-to-face. The services studied here are viewed mostly as a recruitment tool for traditional mental health services: "The fact that you write to us is very good! You need someone to talk to and receive help in order to gain happiness and live a better life." This is readily understandable. The talking cure embodies a long and successful tradition that stretches from Socrates to Sigmund Freud. Research strongly supports the benefit of the talking cure, ${ }^{34,35}$ and one service remarked that "problems are always reduced whenever we share them with someone else. ..." Furthermore, it might be impossible for some services to answer all of the messages they receive, let alone follow up in a respectful and professional manner: "Remember that many people are in need of help. Hence, you may only pose five questions per month. Check if others have asked about the same as you." The services may additionally recognize their own limitations in trying to help people engaged in life struggles and sometimes negotiating with death itself. The risk of self-harm increases in isolation. Therefore, advice to talk may emphasize the importance of not being alone: "You should not go alone and feel unhappy."

However, such advice is less understandable in the context of what people value in online counseling. Several studies suggest that young people prefer the Internet to face-to-face services. They answer more sincerely and are more comfortable with self-disclosure online. ${ }^{32,36-38}$ Anonymity seems important. ${ }^{12}$ Some people prefer written communication, ${ }^{36,39}$ and research emphasizes the importance of having sufficient time to express an agenda..$^{32,40-42}$ Indeed, services often tell people to bring their written messages to a face-to-face counseling session: "If you have trouble expressing yourself you might write your thoughts on a paper and give it to those who should help you." The recommendation of "talk and tell" becomes even harder to understand when a service user clearly describes a bad experience with talking to others or finds talking to professionals particularly challenging:

"I have talked with the nurse, psychologist, doctor, teacher and counselor, but I don't feel it helps. The reason why I don't feel it helps might be that I don't manage to open up and tell what really bothers me."

In this context, advice to "try again" can undermine services' goal of providing an alternate route for human communication. In contrast with the written word's hidden agenda of modernity and victory, ${ }^{43}$ oral communication dominates the text of Internet-based mental health services. Hence, is it not possible to "talk" about life struggles in a meaningful way in written communication? Some services highlight the sincerity 
and openness of their users' writing and try to facilitate a dialog online. Some psychotherapy theories and traditions value the written text, ${ }^{44}$ and several service users emphasized that recovery might follow written reflections. ${ }^{45}$ However, that is not a dominant position. This might reflect a young field and profile of the services included in this research.

\section{The preferred "other"}

Internet-based mental health services consistently recommend that service users should talk to someone face-toface. To whom are they advised to talk? "I think you should talk to your friend and tell him how much you want to help." The users are sometimes encouraged to face their loved ones and talk to them directly. However, this is not the most dominant advice. The services mostly recommend seeking in-person advice from someone not directly involved with the actual problem. Thus, one might interpret the main message as "talk to someone else." However, the services seem to have different advice regarding who else the submitters should talk to; it is even possible to trace a hierarchy in this matter.

First and foremost, counselors encourage service users to talk to parents, other family members, and friends. Although ambiguous, this advice is very prevalent. When friends and family members approach services for advice about someone's problems, the counselors typically answer that:

"[It] is incredibly hard to be a relative to a person with mental problems. You want to do something to improve the situation for the one you love but somehow it only gets worse no matter what. You have lived with him for 27 years. That is a long time. ... As I see it, you need to focus on yourself and less on your husband and his depression. He needs to take more responsibility for his disease - in cooperation with the hospital."

Family and friends might help, but there are limits to what they can do. On one hand, they might get too involved; on the other hand, they might become exhausted. Accordingly, all the services strongly advise users to talk to professionals: "If you cannot talk to your parents, start contacting the counselor at school, school nurse or someone grown up at school!" Most commonly, they advise adolescents and students to talk to the school nurse and tell adults to talk to the doctor. Few services recommend other resources (eg, social workers, psychologists, priests, philosophers, librarians, musicians). Importantly, we noted some cultural differences in this regard: Swedish websites seem more diverse in their recommendations, valuing the existence of the social curator. However, most answers empower health professionals as experts regarding life struggles and identify them as the ones to consult when encountering trouble.

This conviction seems more highly developed among the counselors than service users. A service user who works in health care wrote about the potential for misinterpretation:

"After many years of doubt, I have finally accepted assistance from the mental health services and learned today that they had to give me a diagnosis in order to help. Why? ... The thought of having a psychiatric diagnosis really scares the hell out of me."

The counselor answered by saying:

"I don't really understand why you are so afraid of getting your troubles assessed in diagnostic terms? In order to get treatment it will be significant that the person actually has some problems in need of assistance."

These differences in perspectives are interesting. Services seem to anticipate that only diagnosed conditions are worthy of professional assistance and communicate that a psychiatric diagnosis is nothing to fear. Hence, the answers lack support from other service users writing about self-stigmatization ${ }^{46}$ and feeling ashamed when life struggles are transformed into questions of disease ${ }^{8}$ and identified from research. ${ }^{47,48}$ Accordingly, some answers might reinforce a notion of Internet-based services as an uncritical part of the health care system, diminishing their credibility.

\section{Recommendations for self-care}

Seek help and talk to health care professionals is the most dominant recommendation to the service users but not the only one. The services often include recommendations for self-care. Answers from Internet-based mental health services often urge patience, kindness, and self-acceptance. They advise service users to lower their expectations and demand less of themselves, and to keep hoping for a better future:

"What you are going through is in fact a very hard struggle, you need to exercise, exercise, exercise in order to act differently, and you need to find other ways to cope with your anxiety. Distract yourself, be active and mindful. Sometimes you manage, other times not. But you must not give up; you need to continue the fight. And above all, acknowledge your own struggle, be kind to yourself, treat yourself as if you were your best friend having a hard time." 
Other services stress the importance of self-responsibility and reducing belief in external resources: "You will not meet magicians who conjure up a wonderful life for you. You - and me - we need to do it ourselves." Thus, the overall message is that "you have to take care of yourself." Moreover, services offer different techniques to promote self-care:

"You, struggling with life, having no friends, it is quite natural. As human beings we are determined to be social creatures; being together, sharing work, adventures and the company of others. Even if many people in our society practically might function on their own, we need human relations in order to flourish in life."

One of the most important recommendations is to be social and share experiences and important moments with other people. They urge submitters to fill their lives with activities that involve other people, to spend time with friends, visit cafés, go to the movies, get a hobby, join a voluntary organization, and so forth. In other words, social activity reduces life struggles. Furthermore, some services ask whether the submitters sleep and eat regularly and sufficiently, participate in physical activity at some time during the day, and whether or not they go to school/work and as such have something meaningful to attend to during the day: "To prevent depression, circadian rhythm, regular meals and physical activity are all important factors in everyday life."

As discussed earlier, counselors sometimes encourage submitters to read text written by people with similar life struggles. Moreover, they urge submitters to document their own thoughts, feelings, and experiences: "Writing a diary of how you feel when life is good or bad, is one way of discovering patterns in your life." The idea seems to be that writing might reveal a pattern, and clarity and consciousness might promote changes for a better life. Services suggest systematic self-exploration as a way for service users to see themselves more clearly:

"I realize that what I write to you will be thoroughly examined and you might suspect that I am somebody from Shutter Island. Consequently, I believe you might enjoy reading books other teenagers have written about their life struggles. You are not the only one stuck in these kinds of thoughts and emotions. Maybe you should write about your own thoughts and experiences as a way of validating your own view of the world at some distance."

Moreover, some services ask service users to monitor specific patterns and recommend writing as a way to strengthen positive thinking and slowly change the self-reinforcing circles of negative thinking:

"It might be hard to focus on what's not negative in life and it demands some sort of rehearsal. How often do you think of the positive things that happen around you? I would recommend that you each day before going to bed thoroughly consider the following question: What has been the most positive thing that's happened today? Write down the answer, and keep the answers for the time to come. It might be recommendable regularly to read what you have written. It makes it easier to remember the positive things in life."

Other services emphasize the inherent advantages of writing, painting, and drawing: "Many people find these activities relieving for the pain they feel inside. Maybe it could help for you as well?"

These benevolent recommendations are sometimes paradoxical. For example, a submitter who wrote that "I just keep thinking more and more about suicide" was told that "it's important that you don't think so much of suicide but try to keep focused on life here and now." In this context, kindness and benevolence may reinforce misery by emphasizing shortcomings:

"I have tried writing diaries, poems, drawing and jogging against my depression, but I feel that all effect is gone. I have got lots of advice and many tips, but they don't work the way they are supposed to. It is like this, what's working for others, doesn't always work for me. I don't talk so often with the school nurse because something is stopping me.”

The most common response from the services is "try again, harder this time." It sometimes seems that the services have more trust in their own recommendations than what is experienced by the service users.

\section{Reflections on social consequences}

Our interpretations suggest that the services mainly understand their answers to submitters' presenting concerns as individual challenges in life; as such, they recommend individual coping strategies, including seeking help from health care professionals. The Internet-based services described here offered total anonymity and favor individual life narratives. In other words, the attention given to each submitter and his/ her personal situation seems obvious and sensible. However, we will end this article by reflecting upon the social consequences of this dominant discourse. 
The literature frequently discusses the consequences of individualization in relation to public health. ${ }^{18}$ Petersen and Lupton $^{49}$ show how public health practices might understand individualization as part of the entrepreneurial self, as the self who is expected to live life in a prudent, calculating way, and to be ever-vigilant about risk. This interpretation might construct human beings as independent and responsible citizens who make rational choices and actively participate in social and economic life, regardless of social conditions. Increasingly, people's problems are linked to "health," transforming them into issues that require health professionals and individual solutions. According to Petersen and Lupton, ${ }^{49}$ such individualization relates closely to "neo-liberal" policy, which emphasizes the rights and obligations of the customer and diminishes political responsibility for building inclusive societies.

Accordingly, one could question how Internet-based services respond and understand social responsibility. It is possible to view these services as a way of emptying the community of critical voices and silencing oppressed people. In this perspective, Internet-based services might further marginalize oppressed people by making important experiences invisible to the public. Consequently, we will emphasize the services' responsibility to synthesize and enlarge submitters' concerns towards the government and the general public, and hence, appeal for a greater awareness of such services in the public debate.

Furthermore, the answers show that it is possible to exceed the inherent limitations of the services valuing face-to-face and verbally-based services over written and anonymous services. This fact suggests that the answerers are capable of crossing those boundaries of the services, making it possible to speculate about other "ground-breaking" answers. Our previous study defined "life struggle" as the extent to which every citizen is a unique and irreplaceable member of the social community and described it as a struggle for social recognition. ${ }^{13}$ Accordingly, we suggest here that Internet-based mental health services might increase the suppression of already marginalized citizens by not helping them understand how life struggles might overlap social and political factors. In turn, services' answers might unwittingly camouflage the personal and social costs of political decisions. One way of dealing with this paradox is to include references to relevant user organizations in the answers. This way, the services signal an awareness of the scope of the actual concern and show a way into a community of peers. The user movements represent an important community on a local level, enhancing social inclusion and possession of political power that might strengthen the voices of silenced people and enhance the social recognition of marginalized people at a societal level. ${ }^{50}$

In conclusion, our study recognizes the need for a broader perspective in the Internet-based services. The services are challenged to include social explanations in their answers and strengthen their responsibility to amplify peoples' messages at a societal level. Importantly, contributing to the enlargement of silenced voices and building alliances with the ongoing struggle for recognition is a function of democracy.

\section{Acknowledgments}

The project is supported by The Nordic Research Academy in Mental Health at The Nordic School of Public Health. We wish to thank the University of Agder for funding this project. Karen Williams of Kwills Editing Services in Weymouth, MA, assisted us with questions regarding the English language, and we wish to express our gratitude for her important contribution. Moreover, Professor Olle Söderhamn at the University of Agder read drafts of the manuscript and we appreciated his comments.

\section{Disclosure}

The authors report no conflicts of interest in this work.

\section{References}

1. Nutt DJ. Relationship of neurotransmitters to the symptoms of major depressive disorder. J Clin Psychiatry. 2008;69 Suppl E1:4-7.

2. Johannessen B, Skagestad I, Bergkaasa AM. Food as medicine in psychiatric care: which profession should be responsible for imparting knowledge and use of omega-3 fatty acids in psychiatry. Complement Ther Clin Pract. 2011;17(2):107-112.

3. Beck AT, Rush AJ, Shaw BF, Emery G. Cognitive Therapy of Depression. New York, NY: The Guilford Press; 1979.

4. Yalom ID. Momma and the Meaning of Life: Tales of Psychotherapy. London, UK: Piatkus; 2000.

5. Honneth A. The Struggle for Recognition: The Moral Grammar of Social Conflicts. Cambridge, UK: Polity Press; 1995.

6. Wakefield JC. The concept of mental disorder: On the boundary between biological facts and social values. Am Psychol. 1992;47(3): 373-388.

7. Mitchell S. Depression and recovery. J Ment Health. 2010;19(4): 369-372.

8. Andersen AJW, Larsen IB. Hell on earth. Textual reflections on the experience of mental illness. J Ment Health. 2012;21(2):174-181.

9. Vilhelmsson A, Svensson T, Meeuwisse A. Mental ill health, public health and medicalization. Public Health Ethics. 2011;4(3): 207-217.

10. De Wattignar S, Read J. The pharmaceutical industry and the Internet: Are drug company funded depression websites biased? J Ment Health. 2009;18(6):476-485.

11. Conrad P, Schneider JW. Deviance And Medicalization: From Badness to Sickness. 2nd ed. Philadelphia, PA: Temple University Press; 1992.

12. Andersen AJW, Svensson T. Internet-based mental health services in Norway and Sweden - characteristics and consequences. Adm Policy Ment Health. November 23, 2011. [Epub ahead of print.] 
13. Andersen AJW, Svensson T. Struggles for recognition. A content analysis of messages posted on the Internet. $J$ Multidiscip Healthc. 2012;5:153-162.

14. Andersen AJW, Svensson T. The dialogical bricoleur? Expectations towards Internet-based services in Norway and Sweden. Nordic Social Work Research. 2012;2(2):137-152.

15. Bryman A. Social Research Methods. 3rd ed. New York, NY: Oxford University Press; 2008.

16. Jørgensen M, Phillips L. Discourse Analysis as Theory and Method. London, UK: Sage Publications; 2002.

17. Jaworski A, Coupland N. The Discourse Reader. London, UK: Routledge; 1999.

18. Andersen AJW. Governing health. Discourse analysis in public health research. In: Salvini A, Andersen AJW, editors. Interaction, Health and Community. Theories and Practices from Italy and Norway. Pisa, Italy: Edizioni Plus Pisa University Press; 2011.

19. Gubrium JF, Holstein J. The constructionist mosaic. In: Holstein JA, Gubrium JF, editors. Handbook of Constructionist Research. New York, NY: The Guilford Press; 2008.

20. Foucault M. The Archaeology of Knowledge. London, UK: Tavistock Publications; 1972.

21. Gill R. Discourse analysis: practical implementation. In: Richardson JTE, editor. Handbook of Qualitative Research Methods for Psychology and the Social Sciences. Leicester, UK: British Psychological Society; 1996.

22. Potter J, Wetherell M. Discourse and Social Psychology: Beyond Attitudes and Behaviour. London, UK: Sage; 1987.

23. Huckin TN. Textual silence and the discourse of homelessness. Discourse Society. 2002;13:347-372.

24. Moncrieff J, Cohen D, Mason JP. The subjective experience of taking antipsychotic medication: a content analysis of Internet data. Acta Psychiatr Scand. 2009;120(2):102-111.

25. Wiener DB. Betrayal! The 1806 English Translation of Pinel's Traité medico-philosophique sur l'aliénaton mentale ou la manie. Gesnerus. 2000;57:42-50.

26. Berry B, Buck P, Mills M, Stipe M. Everybody hurts [Recorded by R.E.M.]. On: Automatic for the People [CD]. New York, NY: Warner Music; 1992.

27. Kaptchuk TJ. Chinese Medicine. The Web that has no Weaver. London, UK: Rider; 1989.

28. Kristoffersen K. Human rhythms in a health perspective. Norsk Tidsskrift for Sykepleieforskning. 2003;5(4):211-224. [Norwegian.]

29. Rickwood DJ, Deane FP, Wilson CJ. When and how do young people seek professional help for mental health problems? Med J Aust. 2007;187(7):S35-S39.

30. Burns J, Morey C, Lagelee A, Mackenzie A, Nicholas J. Reach out! Innovation in service delivery. Med J Aust. 2007;187(7):S31-S34.

31. Burns JM, Durkin LA, Nicholas J. Mental health of young people in the United States: what role can the Internet play in reducing stigma and promoting help seeking? J Adolesc Health. 2009;45(1):95-97.
32. Richards D. Features and benefits of online counselling: Trinity College online mental health community. Br J Guid Counc. 2009;37(3): 231-242.

33. Ybarra ML, Suman M. Help seeking behavior and the Internet: a national survey. Int J Med Inform. 2006;75(1):29-41.

34. Wampold B. The Great Psychotherapy Debate: Models, Methods, and Findings. Mahwah, NJ: Lawrence Erbaum and Associates; 2001.

35. Miller SD, Hubble MA, Duncan BL, editors. The Heart and Soul of Change: What Works in Therapy? Washington, DC: American Psychological Association; 1999.

36. Cook JE, Doyle C. Working alliance in online therapy as compared to face-to-face therapy: preliminary results. Cyberpsychol Behav. 2002; 5(2):95-105.

37. Farrell SP, McKinnon CR. Technology and rural mental health. Arch Psychiatr Nurs. 2003;17(1):20-26.

38. Griffiths F, Lindenmeyer A, Powell J, Lowe P, Thorogood M. Why are health care interventions delivered over the Internet? A systematic review of the published literature. J Med Internet Res. 2006;8(2):e10.

39. Umefjord G, Petersson G, Hamberg K. Reasons for consulting a doctor on the Internet: web survey of users of an ask the doctor service. J Med Internet Res. 2003;5(4):e26.

40. Mehta S, Chalhoub N. An e-mail for your thoughts. Child Adolesc Ment Health. 2006;11(3):168-170.

41. Sheese BE, Brown EL, Graziano WG. Emotional expression in cyberspace: searching for moderators of the Pennebaker disclosure effect via e-mail. Health Psychol. 2004;23(5):457-464.

42. Valentine G, Holloway SL. Cyberkids? Exploring children's identities and social networks in on-line and off-line worlds. Ann Assoc Am Geogr. 2009;92(2):302-319.

43. Toulmin S. Cosmopolis: The Hidden Agenda of Modernity. Chicago, IL: University of Chicago Press; 1990.

44. White M. Maps of Narrative Practice. New York, NY: Norton; 2007.

45. Larsen IB, Andersen AJW. A holy duty. How do users of the mental health care system describe themselves, and what are their reasons for turning their experiences into written text? Klin Sygepleje. 2011;25(1):38-47. [Danish.]

46. Deegan PE. Recovering our sense of value after being labelled mentally ill. J Psychosoc Nurs Ment Health Serv. 1993;31(4):7-11.

47. Barham P, Hayward R. Relocating Madness. From the Mental Patient to the Person. London, UK: Free Association Books; 1995.

48. Kutchins H, Kirk SA. Making Us Crazy: DSM: The Psychiatric Bible and the Creation of Mental Disorders. New York, NY: Free Press; 1997.

49. Petersen A, Lupton D. The New Public Health: Health and Self in the Age of Risk. London, UK: Sage; 1996.

50. Bracken P, Thomas P. Postpsychiatry. Mental Health in a Postmodern World. Oxford, UK: Oxford University Press; 2005.
Psychology Research and Behavior Management

\section{Publish your work in this journal}

Psychology Research and Behavior Management is an international, peerreviewed, open access journal focusing on the science of psychology and its application in behavior management to develop improved outcomes in the clinical, educational, sports and business arenas. Specific topics covered include: Neuroscience, memory \& decision making; Behavior

\section{Dovepress}

modification \& management; Clinical applications; Business \& sports performance management; Social and developmental studies; Animal studies. The manuscript management system is completely online and includes a quick and fair peer-review system. Visit http://www.dovepress. com/testimonials.php to read real quotes from published authors. 